\title{
Performance of a Pre-Procedural Mehran Score to Predict Acute Kidney Injury After Percutaneous Coronary Intervention
}

\author{
Faisal Rahim ${ }^{1,2}$, Anamarys Blanco ${ }^{1,2 *}$, Michelle Nguyen $^{1,2}$, Steven Quach $^{1,2}$, Sai Guduru ${ }^{1,2}$, \\ Shraddha Makadia ${ }^{1,2}$ and Khalid Abusaada ${ }^{1,2}$ \\ ${ }^{1}$ University of Central Florida College of Medicine, USA
}

${ }^{2}$ Ocala Regional Medical Center Internal Medicine Residency Program, USA

*Corresponding author: Anamarys Blanco, University of Central Florida College of Medicine, Ocala Regional Medical

Center Internal Medicine Residency Program, USA

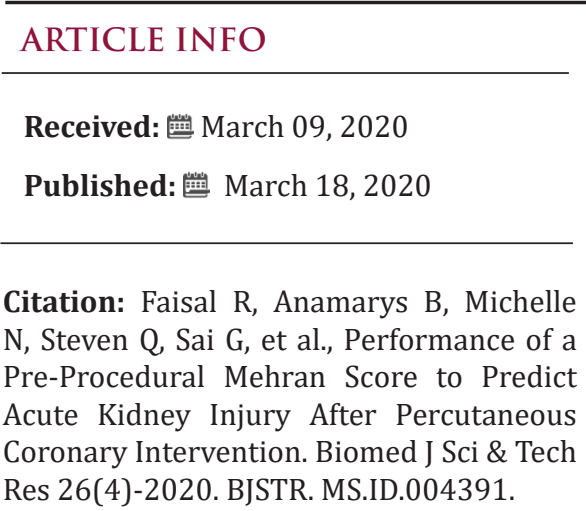

\section{ABSTRACT}

Acute kidney injury (AKI) is a known complication of patients undergoing cardiac catherization or Percutaneous Coronary Interventions (PCI), affecting up to $14 \%$ of patients, and is associated with increased overall mortality and risk of cardiac events. The Mehran score was developed to identify patients that are at risk for AKI after cardiac catheterization or PCI, but its use of contrast volume as part of the score calculation limits its application prior to the procedure. In this study, we evaluated the utility of a modified Mehran score that utilizes only pre-procedural data by excluding contrast volume. This was done in a retrospective fashion using data from patients who received PCI at our institution between July 2015 and December 2017 by evaluating the discriminative ability of the scoring systems for predicting outcomes through a receiver-operator characteristic curve analysis. We found that, despite a small loss in discrimination, there was no difference in the four-category net discrimination index between the two scores. The pre-procedural modified Mehran score is a useful clinical predictor of the risk of AKI in patients undergoing PCI with a sensitivity of $95 \%$ for the low risk group and specificity of $96 \%$ for the high-risk group. Due to the readily available risk score components it allows for immediate identification of high-risk patients prior to PCI and application of renal protective measures prior to the procedure at an appropriate and timely manner.

Keywords: Mehran Score; Acute Kidney Injury; Cardiac Catheterizations; Percutaneous Coronary Interventions

\section{Introduction}

More than two million cardiac catheterizations and percutaneous coronary interventions (PCI) are performed in the United States each year [1]. Acute Kidney Injury (AKI) is a common complication in these patients, affecting 3-14\% of cases [2]. AKI after PCI is associated with increased mortality, increased risk of cardiac events, progression of chronic kidney disease (CKD), prolonged hospital stay, and higher healthcare costs [3-8]. The National Quality Forum established a patient safety objective to reduce the prevalence of
AKI related to contrast administration [9] and the Kidney Disease Improving Global Outcomes (KDIGO) published guidelines for AKI prevention, which include screening for patients at risk and initiating volume expansion in those at high risk [10]. Multiple scores have been developed to identify patients at risk for AKI after cardiac catheterization or PCI. The Mehran score is one such scores that was developed and validated in 2004 [11]. One advantage of the Mehran score is ease of use; it is composed of eight variables with each having an integer score, the sum of which correlate to one 
of four levels of risk. However, its use of contrast volume in score calculation limits its application before the procedure. Knowing the risk prior to catheterization would allow upstream initiation of renal-protective strategies and may decrease the rates of AKI. In this study we evaluated the utility of a modified Mehran score that utilizes only pre-procedural data.

\section{Methods}

\section{Study Population}

The NCDR CathPCI Registry is sponsored by the American College of Cardiology (ACC) and the Society for Cardiovascular Angiography and Intervention [12]. The registry includes data on patient demographics, clinical presentation, procedures, treatments, outcomes, and mortality associated with PCI. Variable definitions and more information can be found at the ACC NCDR web site (http:// www.acc.org/ncdr/cathlab.htm). This is a retrospective study using data from patients who received PCI at our institution between July 2015 and December 2017. Patients were excluded if they had diagnostic catheterization without PCI. In addition, patients with missing variables required to calculate the predictive scoring models, and patients on dialysis at the time of PCI were also excluded from the analysis.

\section{Definitions}

The Mehran score incorporates 8 variables: hypotension, intra-aortic balloon pump (IABP), Congestive Heart Failure (CHF), age $>75$ years old, anemia, diabetes mellitus, contrast volume, and serum creatinine $>1.5 \mathrm{mg} / \mathrm{dl}$ or Estimated Glomerular Filtration Rate (eGFR) $<60 \mathrm{ml} / \mathrm{min} / 1.73 \mathrm{~m} 2$ [11]. The Acute Kidney Injury Network (AKIN) definition of AKI was used - an absolute increase in serum creatinine of $\geq 0.3 \mathrm{mg} / \mathrm{dL}$ or $\geq 1.5$-fold from pre-PCI serum creatinine. Pre-PCI serum creatinine was measured within the last month of the PCI and post-PCI serum creatinine was measured up to 30 days after PCI. Baseline serum creatinine was used to categorize patients into eGFR >60, 40-60, 20-40, or <20 ml/min 1.73 $\mathrm{m} 2$. eGFR in $\mathrm{mL} / \mathrm{min}$ per $1.73 \mathrm{~m} 2$ was calculated using the MDRD estimate of kidney function as $175 \mathrm{X}$ Serum Creatinine-1.154 X age0.203 (X 1.212 if patient is black) (X 0.742 if female). Anemia was defined using the World Health Organization definition of hemoglobin $<13 \mathrm{~g} / \mathrm{dl}$ for males and $<12 \mathrm{~g} / \mathrm{dl}$ for females [13]. Hypotension was documented if the patient had cardiogenic shock within 24 hours prior to PCI and/or the use of peri-procedure Intra-Aortic Balloon Pump (IABP). The pre-procedural Mehran score used the same variables as the original, except for contrast volume which was excluded. Hypotension was defined as a systolic blood pressure less than $90 \mathrm{~mm} \mathrm{Hg}$ for more than 30 minutes and/or cardiac index below $2.2 \mathrm{~L} / \mathrm{min} / \mathrm{m} 2$ secondary to cardiac dysfunction and/ or requirement of parenteral inotropes/vasopressors or mechanical support including intra-aortic balloon pump, extracorporeal cir- culation, ventricular assist devices to maintain blood pressure and cardiac index above the levels.

\section{Statistical Analysis}

Baseline characteristics and outcomes were summarized by frequency tabulation and means with standard deviations as appropriate. Discriminative ability of the scoring systems for predicting outcomes was evaluated by receiver-operator characteristic curve analysis. The Area Under the Receiver-Operating Characteristic Curve (AUROC) was calculated and compared between the Mehran score and the pre-procedural Mehran score using the DeLong test [14]. Mehran score was categorized into 4 risk groups (low risk $<6$ points, Moderate risk 6-10 points, high risk 11-15 points, and very high risk $>15$ ) based on the original study by Mehran et al [11]. Estimates of sensitivity, specificity, and positive and negative predictive values were calculated for each score. Comparison between risk groups for each score was performed using the chi score test. All statistical comparisons were 2 tailed, with value $<0.05$ considered statistically significant. The data analysis was performed using STATA, version 13.0 (StataCorp, College Station, TX).

\section{Results}

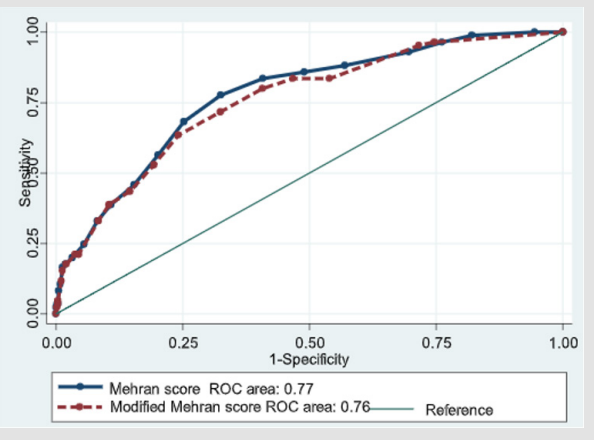

Figure 1: Comparison of the area under the receiveroperating characteristic curve of the original vs preprocedural Mehran score.

1. AUROC was calculated using the DeLong test.

2. Removal of contrast volume from the Mehran score resulted in a small loss of discrimination, 0.77 in original Mehran score vs 0.76 in Modified Mehran score with a p-value of 0.0126 .

1511 patients were included in the study. A total of 70 (4.6\%) patients developed AKI. Baseline demographic and clinical characteristics are included in Table 1. Calculation of the original and pre-procedural Mehran score are outlined in Table 2. The original Mehran score's risk categories were low (score $\leq 5$ ), moderate (6$10)$, high [11-16], and very high ( $\geq 16)$. The pre-procedural Mehran score categories were low ( $\leq 2)$, moderate (3-8), high [8-12], and very high $(\geq 13)$. AKI risk within each category is described in Table 3. AKI risk was comparable within categories between both Mehran scores. The risk of AKI in the low risk groups was $1.58 \%$ and $0.96 \%$ 
in the original and pre-procedural Mehran groups, respectively. The risk in the high-risk groups was $17.31 \%$ and $14.29 \%$, respectively (Table 3). The removal of contrast volume from the Mehran score resulted in a small loss of discrimination as seen in Figure 1 (AUROC 0.774 vs $0.758, p=0.0126$ for the original Mehran and the modified Mehran respectively). However, there was no difference in the four-category Net Discrimination Index (NRI) $(-0.11, \mathrm{p}=0.15)$ between the two scores. Integrated Discrimination Index (IDI) for the modified score was $0.0063(\mathrm{p}=0.001)$ indicating a small loss in predictive accuracy. The pre-procedural Mehran score resulted in a sensitivity of $95 \%$ for the low risk group (score $\leq 2$ ) and a specificity of $96 \%$ for the high-risk group (score $\geq 13$ ).

Table 1: Demographic and clinical data.

\begin{tabular}{|c|c|}
\hline Demographics & n $(\%)$ \\
\hline Gender, Male & $924(61.15 \%)$ \\
\hline \multicolumn{2}{|c|}{ History \& Medical Conditions } \\
\hline Smoker & $360(23.83 \%)$ \\
\hline Hypertension & $1397(92.46 \%)$ \\
\hline Dyslipidemia & $1302(86.17 \%)$ \\
\hline Prior Myocardial Infarction & $520(34.41 \%)$ \\
\hline Prior Heart Failure & $336(22.24 \%)$ \\
\hline Prior PCI & $735(48.64 \%)$ \\
\hline Diabetes Mellitus & $662(43.81 \%)$ \\
\hline Prior Coronary Artery Bypass Grafts & $15(0.99 \%)$ \\
\hline Anemia & $486(32.16 \%)$ \\
\hline \multicolumn{2}{|c|}{ Clinical Evaluation } \\
\hline \multicolumn{2}{|l|}{ Anginal class within the prior 2 weeks } \\
\hline No symptoms & $21(1.39 \%)$ \\
\hline CCSI & $13(0.86 \%)$ \\
\hline CCSII & $83(5.50 \%)$ \\
\hline CCSIII & $660(43.71 \%)$ \\
\hline CCSIV & $733(48.54 \%)$ \\
\hline Heart failure within the prior 2 weeks & $183(12.11 \%)$ \\
\hline Class I & $87(47.54 \%)$ \\
\hline Class II & $48(26.23 \%)$ \\
\hline Class III & $44(24.04 \%)$ \\
\hline Class IV & $4(2.19 \%)$ \\
\hline Acute Coronary Syndrome & $1024(67.77 \%)$ \\
\hline Cardiogenic Shock within 24 hours & $12(0.79 \%)$ \\
\hline Cardiac Arrest within 24 hours & $17(1.13 \%)$ \\
\hline \multicolumn{2}{|c|}{ Procedural Characteristics } \\
\hline Underwent PCI & $1511(100 \%)$ \\
\hline IABP & $15(0.99 \%)$ \\
\hline AKI & $70(4.64 \%)$ \\
\hline
\end{tabular}

PCI: Percutaneous Coronary Intervention; CCS: Canadian Cardiovascular Society classification

Table 2: Original vs Pre-procedural Mehran Score

\begin{tabular}{|c|c|c|}
\hline Risk Factors & Integer Score (Original) & Integer Score (Pre-procedural) \\
\hline Hypotension & 5 & 5 \\
\hline IABP & 5 & 5 \\
\hline CHF & 5 & 4 \\
\hline Age $>75$ years & 4 & 5 \\
\hline
\end{tabular}




\begin{tabular}{|c|c|c|}
\hline Anemia & 3 & 3 \\
\hline Diabetes & 3 & 3 \\
\hline Contrast media volume & 1 per $100 \mathrm{cc} / \mathrm{A}$ \\
\hline Serum creatinine $>1.5 \mathrm{mg} / \mathrm{dl}$ & 4 & 4 \\
OR & 2 for $40-60$ & 2 for $40-60$ \\
\cline { 2 - 3 } eGFR $<60 \mathrm{ml} / \mathrm{min} / 1.73 \mathrm{~m}^{\wedge} 3$ & 4 for $20-40$ & 4 for $20-40$ \\
& 6 for $<20$ & 6 for $<20$ \\
\end{tabular}

Table 3: Incidence of AKI in Mehran and Modified Mehran score categories.

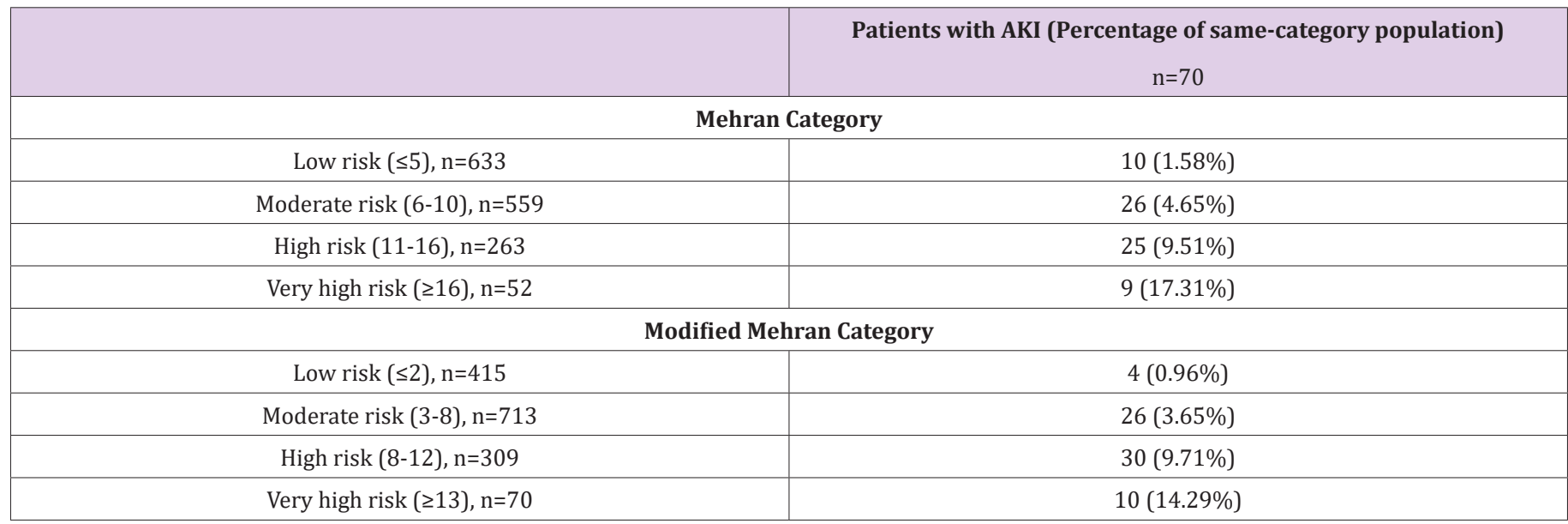

\section{Discussion}

In this study the performance of a modified preprocedural Mehran score was comparable to the performance of the original Mehran score. Mehran et al. reported a risk score for prediction of CIN after PCI in 2004 which has become widely used [11,16-17]. The Mehran score has shown superior clinical utility and usability compared to several alternatives [18-27]. Recent studies have demonstrated the external validity of the Mehran score in populations from Spain, Japan, India, and those undergoing computed tomography imaging or transcatheter aortic valve implantation [2834]. Furthermore, the Mehran score was validated to predict CIN in the setting of non-urgent PCI as well as primary PCI in patients with acute myocardial infarction [33,35]. However, the inclusion of contrast volume, which cannot be obtained until after the procedure, limits the utility of this score as a predictor of AKI before the procedure. Our study shows that the modified Mehran score that excludes contrast volume can still be clinically useful in predicting the risk of AKI. The incidence of AKI in our population was $4.6 \%$, lower than the incidence in the original Mehran study (13.1\%).

This is likely due to the different definition used for AKI in our study, change in contrast media since 2004, or advancements in renal protective strategies in the 14 years between studies. However, our incidence of AKI is similar to other more recent studies although the range of reported incidence has varied widely, from $3 \%$ to $19 \%$ [36]. This wide variation in reported incidences may be due to single-center studies or studies that preceded the current use of volume expansion protocols or iso-osmolar contrast agents and as well as use of varying definitions of AKI [36]. The initial Mehran study and subsequent validation studies looked at CIN, whereas we looked at AKI. CIN was defined as an increase of $\geq 25 \%$ or $\geq 0.5 \mathrm{mg} / \mathrm{dl}$ from baseline creatinine. We used the AKIN definition of AKI; an absolute increase in serum creatinine of $\geq 0.3 \mathrm{mg} / \mathrm{dL}$ or $\geq 1$.5-fold from pre-PCI serum creatinine. The AKIN definition for contrast induced AKI provides a better accuracy in predicting long term mortality than the CIN criteria and it has largely replaced the CIN definition [37]. The original study also measured post-PCI creatinine at 48 hours after the procedure, whereas our study counted elevations in creatinine up to 30 days after the procedure. Applying the original Mehran score with our definitions of AKI, the original score performed better in our study with a c-statistic of 0.77 as compared to a c-statistic of 0.67 in the 2004 study.

Our results show that despite a small loss in discrimination, a pre-procedural Mehran score is a useful clinical predictor of the risk of AKI in patients undergoing PCI with a sensitivity of $95 \%$ for the low-risk group and specificity of $96 \%$ for the high-risk group. The risk score components are readily available which allows for immediate identification of high-risk patients prior to PCI. Identifying high risk patients prior to the procedure allow institution of renal protective measures before the procedure at an appropriate and timely manner. According to multicenter quality improvement intervention in 2014, withholding nephrotoxic medications, stan- 
dardizing fluid orders, and loosening nil per month restrictions, mandatory procedure delays to ensure adequate volume status reduced the rate of AKI by $20 \%$ [38]. Once AKI is established, only supportive measures are currently provided until renal function improves, which leads to prolonged hospital stays, increased mortality, and medical costs. Therefore, the best way to address this complication is prevention. Using the pre-procedural Mehran score, we can identify those considered high risk that are likely to develop AKI and proceed accordingly prior to PCI.

\section{Study Limitations}

Firstly, this is a retrospective study. The results were based on data gathered from a single institution with relatively small sample size, although similar sample sizes were used in the validation studies of the original Mehran score. Definitions of AKI and hypotension were also different from prior studies, as mentioned above. Specifically, the original and subsequent validation studies used CIN, whereas we looked at AKI. The original Mehran study defined hypotension as systolic blood pressure less than $80 \mathrm{mmHg}$ for at least 1 hour requiring inotropic support with medications or IABP within 24 hours peri-procedurally. Hypotension was noted in our study only if the patient had cardiogenic shock within 24 hours prior to PCI and/or the use of peri-procedure IABP.

\section{Conclusion}

In our study, we have found equivalent performance when excluding contrast volume from the Mehran score. These results are relevant clinically, as now the Mehran score can be applied pre-procedure. Despite a small loss in discrimination, clinical utility has been preserved in the pre-procedural Mehran score.

This research was supported (in whole or in part) by HCA Healthcare and/or an HCA Healthcare affiliated entity. The views expressed in this publication represent those of the author(s) and do not necessarily represent the official views of HCA Healthcare or any of its affiliated entities.

\section{References}

1. Go AS, Mozaffarian D, Roger VL, Benjamin EJ, Berry JD, et al. (2013) Heart disease and stroke statistics-2013 update: a report from the American Heart Association. Circulation 127(1): e6-e245.

2. Brown JR, McCullough PA, Splaine ME, Davies L, Ross CS, et al. (2012) How do centres begin the process to prevent contrastinduced acute kidney injury: a report from a new regional collaborative. BMJ quality \& safety 21(1): 54-62.

3. Brown JR, Robb JF, Block CA, Schoolwerth AC, Kaplan AV, et al. (2010) Does safe dosing of iodinated contrast prevent contrast-induced acute kidney injury. Circ Cardiovasc Interv 3(4): 346-350.

4. Chertow GM, Burdick E, Honour M, Bonventre JV, Bates DW (2005) Acute kidney injury, mortality, length of stay, and costs in hospitalized patients. J Am Soc Nephrol 16(11): 3365-3370.

5. James MT, Samuel SM, Manning MA, Tonelli M, Ghali WA, et al. (2013) Contrast-induced acute kidney injury and risk of adverse clinical outcomes after coronary angiography: a systematic review and metaanalysis. Circ Cardiovasc Interv 6(1): 37-43.

6. Lorenzo A, Candilio L, McCullough PA, Colombo A (2017) Current Risk of Contrast-Induced Acute Kidney Injury After Coronary Angiography and Intervention: A Reappraisal of the Literature. Canadian Journal of Cardiology 33(10): 1225-1228.

7. Levy EM, Viscoli CM, Horwitz RI (1996) The effect of acute renal failure on mortality. A cohort analysis. JAMA 275(19): 1489-1494.

8. Rihal CS, Textor SC, Grill DE, Berger PB, Ting HH, et al. (2002) Incidence and prognostic importance of acute renal failure after percutaneous coronary intervention. Circulation 105(19): 2259-2264.

9. (2007) National Quality Forum. Safe practices for better healthcare 2006 Update, Washington, DC: National Quality Forum.

10. Lameire N, Kellum JA (2013) Contrast-induced acute kidney injury and renal support for acute kidney injury: a KDIGO summary (Part 2). Crit Care 17(1): 205

11. R Mehran, ED Aymong, E Nikolsyk, Lasic Z, Iakovou I, et al. (2004) A simple risk score for prediction of contrast-induced nephropathy after percutaneous coronary intervention: development and initial validation. J Am Coll Cardiol 44(7): 1393-1399.

12. Brindis RG, Fitzgerald S, Anderson HV, Shaw RE, Weintraub WS, et al. (2001) The American College of Cardiology-National Cardiovascular Data Registry (ACC-NCDR): building a national clinical data repository. J Am Coll Cardiol 37(8): 2240-2245.

13. (1968) Nutritional anemias. Report of a WHO scientific group. World Health Organ Tech Rep Ser 405: 5-37.

14. DeLong ER, DeLong DM, Clarke Pearson DL (1988) Comparing the areas under two or more correlated receiver operating characteristic curves: a nonparametric approach. Biometrics 44(3): 837-845.

15. McCullough PA, Sandberg KR (2003) Epidemiology of contrast-induced nephropathy. Rev Cardiovasc Med 4(Suppl 5): S3-9.

16. Silver Samuel A, Shah Prakesh M, Chertow Glenn M, Harel Shai, Wald Ron, et al. (2015) Risk prediction models for contrast induced nephropathy: systematic review. BMJ 351: h4395.

17. RA Abellas Sequeiros, S Raposeiras Roubin, E Abu Assi, V Gonzalez Salvado, D Iglesias Alvarez, et al. (2015) Mehran contrast nephropathy risk score: is it still useful 10 years later. J Cardiol 67(3): 262-267.

18. JR Brown, JT DeVries, WD Piper, Robb JF, Hearne MJ, et al. (2008) Serious renal dysfunction after percutaneous coronary interventions can be predicted. Am Heart J 155(2): 260-266.

19. Chen YL, Fu NK, Xu J, Yang SC, Li S, et al. (2014) A simple preprocedural score for risk of contrast-induced acute kidney injury after percutaneous coronary intervention. Catheter Cardiovasc Interv 83(1): E8-16.

20. Fu N, Li X, Yang S, Chen Y, Li Q, et al. (2013) Risk score for the prediction of contrast induced nephropathy in elderly patients undergoing percutaneous coronary intervention. Angiology 64(3): 188-194.

21. Ghani AA, Tohamy KY (2009) Risk score for contrast induced nephropathy following percutaneous coronary intervention. Saudi J Kidney Dis Transpl 20(2): 240-245.

22. Gurm HS, Seth M, Kooiman J, Share D (2013) A novel tool for reliable and accurate prediction of renal complications in patients undergoing percutaneous coronary intervention. J Am Coll Cardiol 61(22): 22422248 .

23. Gao YM, Li D, Cheng H, Chen YP (2014) Derivation and validation of a risk score for contrast-induced nephropathy after cardiac catheterization in Chinese patients. Clin Exp Nephrol 18(6): 892-898.

24. Maioli M, Toso A, Gallopin M, Leoncini M, Tedeschi D, et al. (2010) Preprocedural score for risk of contrast-induced nephropathy in elective 
coronary angiography and intervention. J Cardiovasc Med 11(6): 444449.

25. Tziakas D, Chalikias G, Stakos D, Apostolakis S, Adina T, et al. (2013) Development of an easily applicable risk score model for contrastinduced nephropathy prediction after percutaneous coronary intervention: a novel approach tailored to current practice. Int J Cardiol 163(1): 46-55.

26. Liu Y, Liu YH, Chen JY, Tan N, Zhou YL, et al. (2015) A simple preprocedural risk score for contrast-induced nephropathy among patients with chronic total occlusion undergoing percutaneous coronary intervention. Int J Cardiol 180: 69-71.

27. Victor SM, Gnanaraj A, S V, Rajendra Deshmukh, Mani Kandasamy, et al. (2014) Risk scoring system to predict contrast induced nephropathy following percutaneous coronary intervention. Indian Heart J 66(5): 517-524

28. Zungur M, Gul I, Tastan A, Damar E, Tavli T1 (2016) Predictive Value of the Mehran Score for Contrast-Induced Nephropathy after Transcatheter Aortic Valve Implantation in Patients with Aortic Stenosis. Cardiorenal Med 6(4): 279-288.

29. Sato A, Hoshi T, Kakefuda Y, Harunari T, Watabe H, et al. (2015) Effect of the Mehran risk score for the prediction of clinical outcomes after percutaneous coronary intervention. J Cardiol 66(5): 417-422.

30. Tonolini M, Rigiroli F, Scorza D (2016) Predicting Risk of ContrastInduced Nephrotoxicity in Hospitalized Patients Undergoing Computed Tomography Using the Mehran Stratification Score. Curr Probl Diagn Radiol 45(3): 238-239.

31. Raingruber B, Kirkland Walsh H, Chahon N, Kellermann M (2011) Using the Mehran risk scoring tool to predict risk for contrast medium-induced nephropathy in patients undergoing percutaneous angiography. Crit Care Nurse 31(1): e17-22.

ISSN: 2574-1241

DOI: $10.26717 /$ BJSTR.2020.26.004391

Anamarys Blanco. Biomed J Sci \& Tech Res (c) (P) This work is licensed under Creative

Submission Link: https://biomedres.us/submit-manuscript.php
32. Wi J1, Ko YG, Shin DH, Kim JS, Kim BK, et al. (2013) Prediction of ContrastInduced Nephropathy With Persistent Renal Dysfunction and Adverse Long-term Outcomes in Patients With Acute Myocardial Infarction Using the Mehran Risk Score. Clin Cardiol 36(1): 46-53.

33. Sgura FA, Bertelli L, Monopoli D, Leuzzi C, Guerri E, et al. (2010) Mehran contrast-induced nephropathy risk score predicts short- and long-term clinical outcomes in patients with ST-elevation-myocardial infarction. Circ Cardiovasc Interv 3(5): 491-498.

34. Valappil SP, Kunjukrishnapillai S, Iype M, Koshy AG, Viswanathan S, et al. (2018) Predictors of contrast induced nephropathy and the applicability of the Mehran risk score in high risk patients undergoing coronary angioplasty-A study from a tertiary care center in South India. Indian Heart J 70(3): 399-404.

35. Wi J, Ko YG, Kim JS, Kim BK, Choi D, et al. (2011) Impact of contrastinduced acute kidney injury with transient or persistent renal dysfunction on long-term outcomes of patients with acute myocardial infarction undergoing percutaneous coronary intervention. Heart 97(21): 1753-1757.

36. Tsai TT, Patel UD, Chang TI, Kennedy KF, Masoudi FA, et al. (2014) Contemporary incidence, predictors, and outcomes of acute kidney injury in patients undergoing percutaneous coronary interventions: insights from the NCDR Cath-PCI registry. JACC Cardiovasc Interv 7(1): $1-9$

37. Marco Centola, Stefano Lucreziotti, Diego Salerno Uriarte, Carlo Sponzilli, Giulia Ferrante, et al. (2016) A comparison between two different definitions of contrast-induced acute kidney injury in patients with ST-segment elevation myocardial infarction undergoing primary percutaneous coronary intervention. Int J Cardiol 210:4-9.

38. Brown JR, Solomon RJ, Sarnak MJ, McCullough PA, Splaine ME, et al. (2014) Reducing contrast-induced acute kidney injury using a regional multicenter quality improvement intervention. Circ Cardiovasc Qual Outcomes 7(5): 693-700

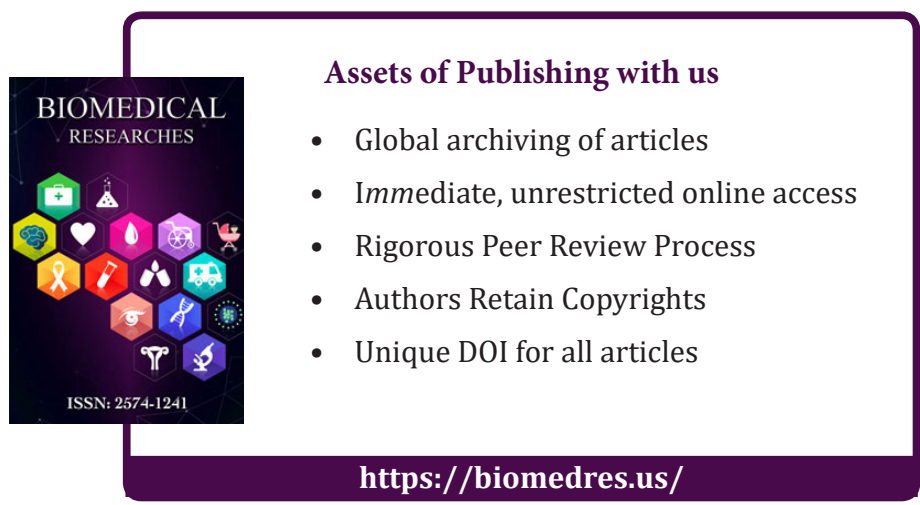

Copyright@ Anamarys Blanco | Biomed J Sci \& Tech Res | BJSTR. MS.ID.004391. 